Vol 11, Issue 6, 2018

\title{
LACTOBACILLUS PARACASEI HIIO1 MEDIATED FERMENTATION OF SYZYGIUM CUMINI L. FRUITS: ASSESSMENT OF CHANGES IN PHENOLIC CONTENT AND ANTIOXIDANT CAPACITY
}

\section{SASITHORN SIRILUN ${ }^{1}$, BHAGAVATHI SUNDARAM SIVAMARUTHI ${ }^{1}$, PERIYANAINA KESIKA ${ }^{1}$, SARTJIN PEERAJAN ${ }^{2}$, CHAIYAVAT CHAIYASUT ${ }^{1 *}$}

${ }^{1}$ Innovation Center for Holistic Health, Nutraceuticals and Cosmeceuticals, Faculty of Pharmacy, Chiang Mai University, Chiang Mai 50200, Thailand. ${ }^{2}$ Health Innovation Institute, Chiang Mai, 50200, Thailand. Email: chaiyavat@gmail.com

Received: 16 February 2018, Revised and Accepted: 14 March 2018

ABSTRACT

Objective: Syzygium cumini L. fruits are reported for several pharmacological applications and winemaking. The present study was conducted to develop and analyze the phytochemical content, and antioxidant properties of lactic acid bacteria mediated fermented S. cumini fruit juice (FSJ).

Methods: The pH of FSJ was measured by pH meter, and total acidity was calculated by titration method. The Folin-Ciocalteu colorimetric method was employed to assess the total phenolic content (TPC), and antioxidant properties were determined by 2, 2'-azino-bis-3-ethylbenzthiazoline-6sulphonic acid, ferric reducing antioxidant power, and ferrous ion-chelating assays.

Results: The formula 1 and 2 displayed pH of 3.23, and 3.12, respectively, after 6 months of fermentation. The acidity of F1 and F2 was regularly increased from 0.23 to 0.55 and 0.29 to $0.53 \mathrm{mg}$ lactic acid equivalent per ml sample, respectively. The TPC of FSJ was progressively increased. The F1 and F2 showed an increase in TPC from 0.94 to 1.61 and 1.05 to $1.95 \mathrm{mg}$ Gallic acid equivalent per ml of sample, respectively. The Formula 1 and 2 exhibited antioxidant capacities of 1.90 and $2.06 \mathrm{mg}$ Trolox equivalent antioxidant capacity per ml sample, 0.81 and 0.80 quercetin equivalent antioxidant capacity per ml sample, and 1.67 and 1.82 Vitamin-C equivalents antioxidant capacity per ml sample, respectively. Ferric reducingantioxidant power of Formula 1 and 2, and Control 1 and 2 were 3.90, 4.29, 2.96, and 3.27 mg Fe2SO4 equivalents per ml of sample, respectively. Whereas, the chelating power of samples was not significantly changed at the end of fermentation.

Conclusion: The high-quality FSJ was prepared with enhanced antioxidant capacity and phenolic compounds. The probiotic containing FSJ is an alternative functional food supplement to prevent, cure and manage several degenerative disorders. Further, clinical studies are essential to insight the functional quality of FSJ.

Keywords: Syzygium cumini L., Phenolic compound, Lactic acid bacteria, Lactobacillus paracasei, Antioxidant, 2, 2'-Azino-bis-3-ethylbenzthiazoline6-sulfonic acid, Ferric reducing antioxidant plasma.

(C) 2018 The Authors. Published by Innovare Academic Sciences Pvt Ltd. This is an open access article under the CC BY license (http://creativecommons. org/licenses/by/4. 0/) DOI: http://dx.doi.org/10.22159/ajpcr.2018.v11i6.25325

\section{INTRODUCTION}

The success of fermented plant juice (FPJ) preparation, regarding quality and safety, significantly depends on starter culture and microbial metabolic reaction on base ingredients. Thus, controlled fermentation with well-characterized starter culture is the advisable technique to produce high-quality FPJ. The starter culture with specific characters like the ability to produce antimicrobials against common foodborne pathogens, and to produce valuable secondary metabolites like $\gamma$-aminobutyric acid (GABA) is the best choice for the production of functional FPJs.

Lactic acid bacteria (LAB) are a group of Gram-positive, cocci or rodshaped, non-spore forming, and acid tolerant bacteria with low guaninecytosine content in the genetic material. Lactobacillus spp. are commonly used as a starter for the preparation of fermented foods. Food isolate of Lactobacillus brevis, Lactobacillus fermentum was reported to produce glutaminase and glutamate decarboxylase [1] and was used as a starter for two-stage fermentation process of Hericium erinaceus to produce GABA rich mushroom juice [2]. Enterococcus faecalis, protease producing $\mathrm{LAB}$ isolated from fermented food, has been used to produce GABA rich H. erinaceus juice [3]. Likely, LAB is used to improve the functional quality of foods. For example, LAB mediated fermentation enhanced the nutritional value and functional property of emblica juice [4].

Syzygium cumini L. belongs to the family Myrtaceae, generally known as jambolan or jamun inherent to the Indian subcontinent. The fruits of jambolan are not available in all the seasons. Thus, researchers concentrating on the development of jambolan fruit based functional foods [5]. Jambolan fruit is largely used in the preparation of vinegar, alcohol beverages, and fermented foods [6]. The leaves of $S$. cumini used as a tea to manage the hyperglycemic condition. S. cumini fruits are rich in antioxidant compounds such as phenolic compounds, anthocyanins, and also contains fermentable sugars $[7,8]$.

Several reports are available on the development of fermented S. cumini beverages, especially wine production [8], and yeast (Saccharomyces cerevisiae) mediated fermented S. cumini was reported to have hypolipidemic, hepatorenal protective, and antidiabetic effects [9].

The reports on LAB fermented S. cumini beverages are very limited. Thus, the present day was conducted to develop Lactobacillus paracasei HII mediated fermented S. cumini juice (FSJ) and evaluated the changes in $\mathrm{pH}$, acidity, total phenolic content (TPC), and total antioxidant capacity (TAC) during fermentation.

\section{METHODS}

Sample, strain, and fermentation

Fresh S. cumini L. fruits and cane sugar were purchased from local market of Chiang Mai province, Thailand. L. paracasei HII01 was obtained from Health Innovation Institute, Chaing Mai, Thailand. 
The fruits were mechanically crushed and used for the fermentation process with cane sugar, and water. The fermentation was carried out with the following experimental setup at room temperature for 6 months, and samples were collected during the fermentation and stored at $-70^{\circ} \mathrm{C}$ after the filtration (Whatman No. 42 filter paper). Formula 1 (F1): S. cumini fruit:Water:Cane sugar (3:10:1 ratio) (Initial pH 6) $+10 \%$ L. paracasei; Formula 2 (F2): S. cumini fruit:water:cane sugar (3:10:1 ratio) (Initial pH 4) $+10 \%$ L. paracasei; Control 1 (C2): S. cumini fruit:water:cane sugar (3:10:1 ratio) (Initial pH 6); and Control 2 (C2): S. cumini fruit:water:cane sugar (3:10:1 ratio) (initial $\mathrm{pH} 4$ ).

The fermentation was conducted at room temperature for 6 months, and samples were collected at the various time point of the fermentation process to assess the changes kinetically. The collected samples were stored at $-70^{\circ} \mathrm{C}$ after filtration with Whatman no. 42 filter paper.

\section{Determination of $\mathrm{pH}$ and acidity}

The $\mathrm{pH}$ and acidity of fermented juice at the various time point of fermentation was evaluated using pH meter (Inola, pH level 2, Weilheim), and titration methods, respectively, as detailed earlier $[4,10]$.

\section{Determination of total polyphenolic content}

The modified Folin-Ciocalteu colorimetric method was employed to measure the TPC of the samples. Briefly, $100 \mu \mathrm{l}$ of $\times 10$ diluted FolinCiocalteu reagent, $1.5 \mathrm{ml}$ of deionized water and $200 \mu \mathrm{l}$ of filtered fermented samples or Gallic acid (used as positive control), at different concentrations, were mixed and incubated at room temperature for 30 min. After incubation, 20\% saturated sodium carbonate was used to stop the reaction, and the absorbance was measured at $725 \mathrm{~nm}$. The phenolic content of the sample was denoted as mg Gallic acid equivalents (GAEs) per $\mathrm{ml}$ of the sample [11].

\section{TAC}

The TAC of fermented samples was measured by 2, 2'-azino-bis-3ethylbenzthiazoline-6-sulphonic acid assay as detailed. The results were denoted as mg Trolox equivalent antioxidant capacity (TEAC), quercetin equivalent antioxidant capacity (QEAC), and Vitamin-C equivalent antioxidant capacity (VCEAC) per ml of the sample [12-15].

\section{Ferric reducing antioxidant power (FRAP) assay}

The samples were subjected FRAP assay. Briefly, sample or standard solution $(60 \mu \mathrm{l})$, FRAP reagent $(1.8 \mathrm{ml})$ and deionized water $(180 \mu \mathrm{l})$ were mixed and incubated at room temperature for $4 \mathrm{~min}$. Then, the reaction mixture was examined using spectrophotometer at $539 \mathrm{~nm}$. The values were denoted as $\mathrm{mg} \mathrm{Fe}_{2} \mathrm{SO}_{4}$ equivalents/ml of the sample [14].

\section{Ferrous ion chelating assay}

The chelating property of fermented samples was calculated. The results were stated as a chelating powder $\left(\mathrm{mg} \mathrm{Fe}_{2} \mathrm{SO}_{4}\right.$ equivalents/ml of sample) [4].

\section{Statistical analysis}

All the investigations were performed in triplicate. The values were represented as mean \pm standard deviation. Duncan's new multiple range tests determined the significant differences, at the $95 \%$ confidential level $(p<0.05)$ by SPSS version 17 (Chicago, SPSS Inc., U.S.A).

\section{RESULTS AND DISCUSSION}

The $\mathrm{pH}$ of FSJ was slowly reduced from initial values. The Formula 1 (Initial pH 5.98) and 2 (Initial pH 4) showed pH of 3.23 and 3.12, respectively, after 180 days of fermentation.

Whereas the control Sample 1 (Initial pH 5.98), and 2 (Initial pH 4) showed $\mathrm{pH}$ of 3.67 and 4.31, respectively, after 180 days of fermentation. The acidity of F1 and F2 was regularly increased from 0.23 to 0.55 and 0.29 to $0.53 \mathrm{mg}$ lactic acid equivalent per $\mathrm{ml}$ sample, respectively. Even control samples showed a slight increase in acidity (0.25-0.28-0.35$0.37 \mathrm{mg}$ lactic acid equivalent per $\mathrm{ml}$ sample) (Fig. 1). The reduction in $\mathrm{pH}$ during fermentation process was due to the catabolism of raw materials by L. paracasei, LAB knew for the release of organics acids during fermentation, which in turn reduce the $\mathrm{pH}$ and increase the acidity.

The TPC of FSJ, both experimental and control samples, was progressively increased. The F1 and F2 showed an increase in TPC from 0.94 to 1.61 and 1.05 to $1.95 \mathrm{mg} \mathrm{GAE}$ per ml of sample, respectively. Likewise, C1 and C2 also exhibited an increase in TPC from 0.67 to 1.30 and 0.63 to $1.46 \mathrm{mg} \mathrm{GAE}$ per $\mathrm{ml}$ of sample, respectively. The results suggested that the FSJ prepared with the starter (L. paracasei) and without starter increase the TPC content, but the concentration of TPC was high in F1 and F2 compared with C1 and C2. Moreover, the initial $\mathrm{pH}$ of the medium play critical role in final TPC concentration, F2 showed high TPC than F1 (Fig. 2).

The TAC of the samples was evaluated concerning the activity of Trolox, quercetin, and Vitamin-C. The Formula 1 and Formula 2 showed 1.90 and $2.06 \mathrm{mg}$ TEAC per ml sample, 0.81 and 0.80 QEAC per ml sample, and 1.67 and 1.82 VCEAC per $\mathrm{ml}$ sample, respectively. The Control 1 and Control 2 exhibited 1.69 and $1.44 \mathrm{mg}$ TEAC per ml sample, 0.71 and 0.60 QEAC per ml sample, and 1.46 and 1.23 VCEAC per ml sample, respectively (Fig. 3).

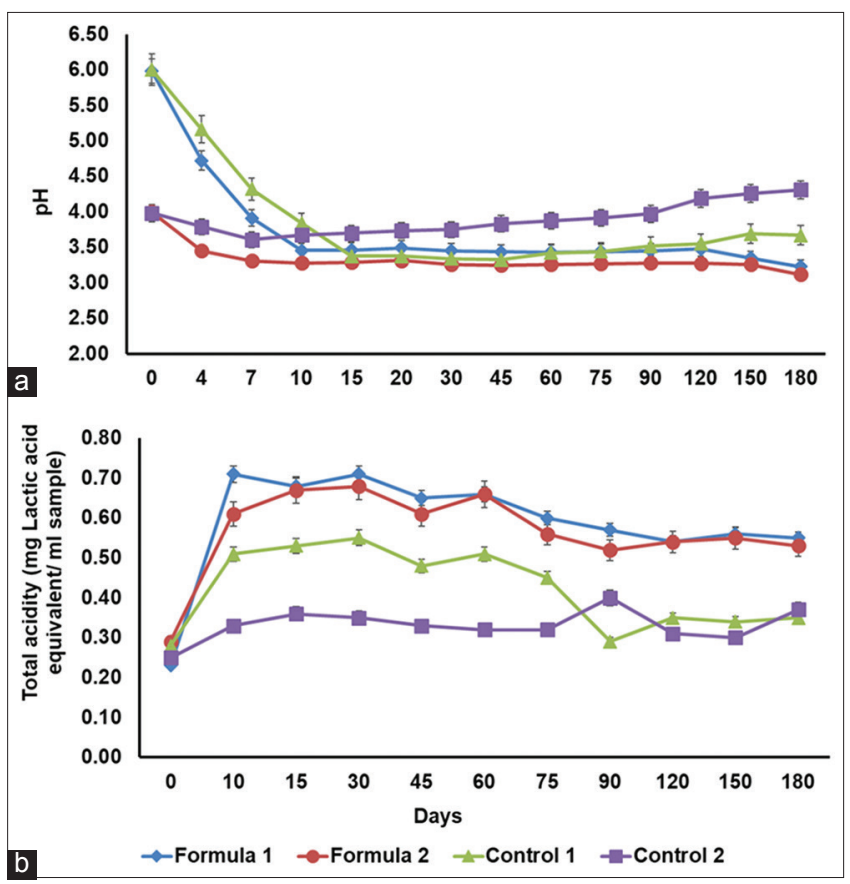

Fig. 1: pH (a) and acidity (b) profile of fermented Syzygium cumini fruit juice

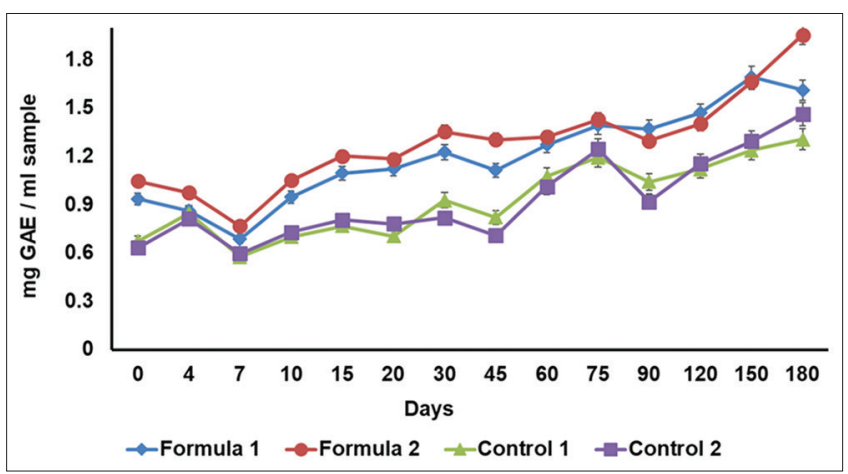

Fig. 2: The total phenolic acid content of fermented Syzygium cumini fruit juice. The results were represented as mg Gallic acid equivalent per $\mathrm{ml}$ of sample 
Ferric reducing-antioxidant power of Formula 1, Formula 2, Control 1, and Control 2 was 3.90, 4.29, 2.96, and $3.27 \mathrm{mg} \mathrm{Fe}_{2} \mathrm{SO}_{4}$ equivalents per $\mathrm{ml}$ of sample, respectively (Fig. 4a). The chelating power of Formula 1, Formula 2, Control 1, and Control 2 was 300.00, $297.08,295.89$, and $300.86 \mathrm{mg} \mathrm{Fe}_{2} \mathrm{SO}_{4}$ equivalents per $\mathrm{ml}$ of sample, respectively (Fig. $4 \mathrm{~b}$ ). The results indicated that both experimental samples and control samples exhibited similar chelating power, and the initial $\mathrm{pH}$ of the medium did not significantly influence the chelating power.

All the parts of $S$. cumini fruits, seeds, leaves, and bark are reported for several beneficial applications. S. cumini was reported for rich antioxidant compounds such as phenolics, flavonoids, carotenoids, and vitamins. S. cumini was active against degenerative diseases and the pigments of $S$. cumini used as a colorant in food industries [16-18].
The methanolic seed extract of $S$. cumini has been reported for antimicrobial activity against Bacillus subtilis, and the activity was associated with damaging the cell wall, reduction in bacterial cell size, and leaking of cellular contents [19].

S. cerevisiae mediated fermented S. cumini stem (FSS) was evaluated for pharmacological importance. The oral supplementation of FSS for 30 days reduced the blood glucose level, improved the lipid profile, atherogenic index, renal and hepatic function in the diabeticinduced rat [9]. S. cumini seed kernel extract (SSKE) was evaluated for $\alpha$-glucosidase activity and found that SSKE was effective inhibitors of $\alpha$-glucosidase, and expands glucose tolerance in Goto-Kakizaki rats [20].

The red wine was prepared with $S$. cumini fruits and yeast, and the quality of the wine was compared with commercial red wine. The results

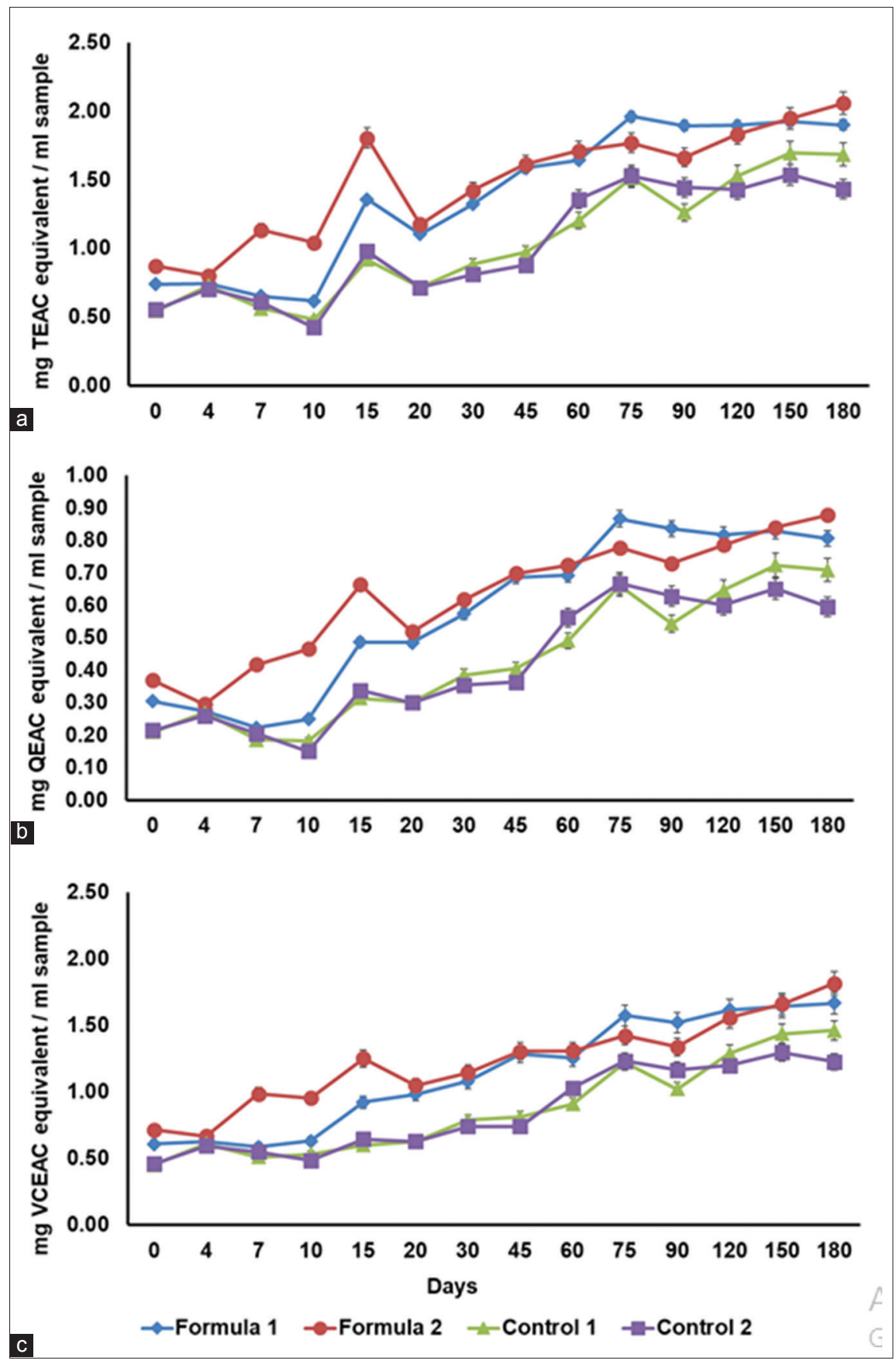

Fig. 3: The total antioxidant capacity of fermented Syzygium cumini fruit juice and values were represented as mg trolox equivalent antioxidant capacity (a) quercetin equivalent antioxidant capacity (b) and Vitamin-C equivalent antioxidant capacity (c) per ml sample 


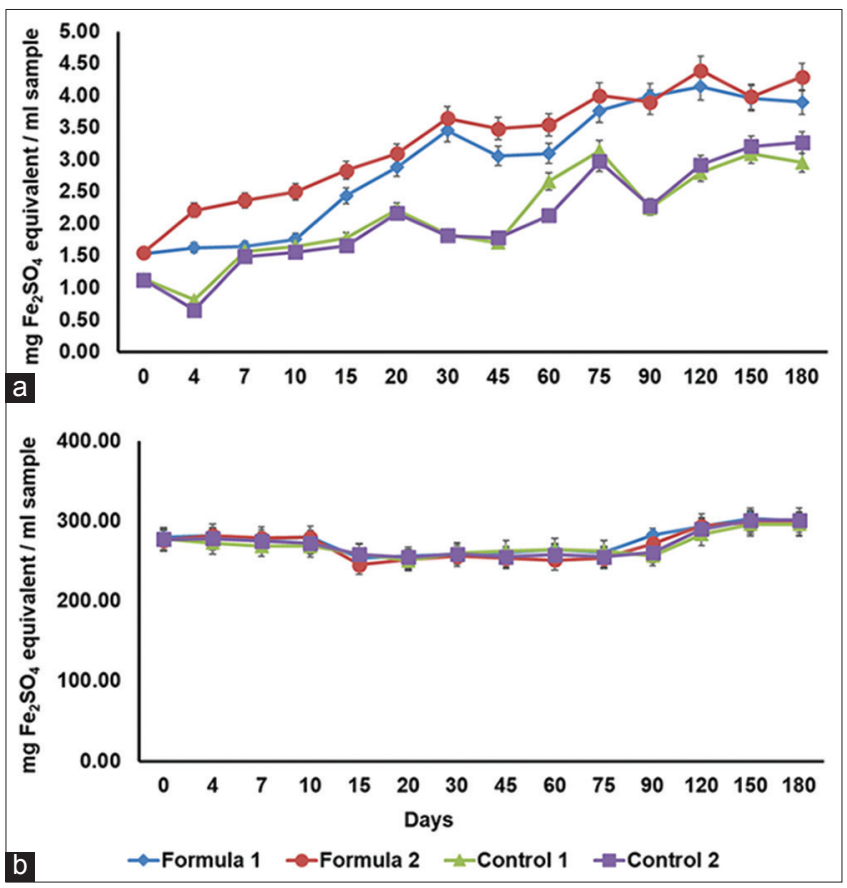

Fig. 4: Ferric reducing antioxidant plasma (a) and chelating power (b) of fermented Syzygium cumini fruit juice

suggested that $S$. cumini wine was rich in tannin, low alcohol content, and accepted as an alcoholic beverage by the healthy volunteers [8]. Brandao et al. [21] also characterized S. cumini fruit wine and reported that the fermentation process, carried out by $S$. cerevisiae, improved the phenolic content, and tannins up to 30 , and $27.4 \%$, respectively.

In vitro evaluation of $S$. cumini leaf extract (SLE) suggested that SLE reduced the acetylcholinesterase, and adenosine deaminase activity. The overall study revealed that SLE reduced the oxidative stress, inflammation, and other diabetic related consequences [22]. The essential oil extracted from leaves and fruits of $S$. cumini have reported for antioxidant and $\alpha$-amylase inhibitory activities [23]. The phytochemicals present in the ethanol extract of stem bark of S. cumini are nontoxic and have pharmacological activities [24].

There was no report on the development of LAB mediated FSJ. The present study was the initial report on L. paracasei FSJ. The results suggested that the TPC and antioxidant capacity of $S$. cumini fruit were significantly increased during fermentation.

\section{CONCLUSION}

We have successfully developed the LAB mediated FSJ and found that the resulting fermented juice rich in phenolic compounds, and antioxidants. The fermentation was conducted for 6 months; the quality of the juice was increased with duration of the fermentation. The initial $\mathrm{pH}$ of the fermentation medium was not suggestively affected the final quality of the product. The probiotic containing FSJ is an alternative functional food supplement to prevent, cure and manage degenerative disorders especially diabetes. Further, clinical studies are necessary to figure out the functional quality of FSJ.

\section{ACKNOWLEDGMENTS}

Authors thankfully acknowledge the Chiang Mai University grant (CMUgrant) for the support and also acknowledge the Faculty of Pharmacy, and Chiang Mai University, Thailand, for the necessary provision. All the authors wish to acknowledge the National Science and Technology Development Agency for the support.

\section{AUTHOR'S CONTRIBUTIONS}

CC involved in the study design and finalization of the manuscript. BSS and PK contributed to data analysis, manuscript preparation, and critical revision of the manuscript. SS and SP are responsible for wet lab experiments. All the authors agree with the content of the manuscript.

\section{CONFLICT OF INTEREST}

There is no conflict of interests.

\section{REFERENCES}

1. Woraharn S, Lailerd N, Sivamaruthi BS, Wangcharoen W, Sirisattha S, Chaiyasut C. Screening and kinetics of glutaminase and glutamate decarboxylase producing lactic acid bacteria from fermented Thai foods. Food Sci Technol (Campinas) 2014;34:793-9.

2. Woraharn S, Lailerd N, Sivamaruthi BS, Wangcharoen W, Sirisattha S, Peerajan S, et al. Evaluation of factors that influence the L-glutamic and $\gamma$-aminobutyric acid production during Hericium erinaceus fermentation by lactic acid bacteria. Cyta J Food 2016;14:47-54.

3. Woraharn S, Lailerd N, Sivamaruthi BS, Wangcharoen W, Peerajan S, Sirisattha $\mathrm{S}$, et al. Development of fermented Hericium erinaceus juice with high content of L-glutamine and L-glutamic acid. Int J Food Sci Technol 2015;50:2104-12

4. Peerajan S, Chaiyasut C, Sirilun S, Chaiyasut K, Kesika P, Sivamaruthi BS. Enrichment of nutritional value of Phyllanthus emblica fruit juice using the probiotic bacterium, Lactobacillus paracasei HII01 mediated fermentation. Food Sci Technol (Campinas) 2016;36:116-23.

5. Akhtar M, Randhawa MA, Iqbal Z. Nutritional therapeutic and food applications of Jamum (Syzygium cumini). Can J Food Sci Technol 2016;1:1-8.

6. Banerjee A, Dasgupta NB. In vitro study of antioxidant activity of Syzygium cumini fruit. Food Chem 2005;90:727-33.

7. Santiago MC, Gouvea AC, Peixoto FM, Borguini RG, Godoy RLO, Pacheco S, et al. Characterization of jamelao (Syzygium cumini (L.) Skeels) fruit peel powder for use as natural colorant. Fruits 2016;71:3-8.

8. Chowdhury P, Ray RC. Fermentation of jamun (Syzgium cumini L.) fruits to form red wine. ASEAN Food J 2007;14:15-23.

9. Swami U, Rishi P, Soni SK. Anti-diabetic, hypolipidemic and hepatorenal protective effect of a novel fermented beverage from Syzygium cumini stem. Int J Pharm Sci Res 2017;8:1336-45.

10. Chaiyasut C, Makhamrueang N, Peerajan S, Sivamaruthi BS. Assessment of organic acid content, and brix value of representative indigenous fermented plant beverages of Thailand. Asian J Pharm Clin Res 2017;10:350-4.

11. Chaiyasut C, Sivamaruthi BS, Pengkumsri N, Keapai W, Kesika P, Saelee $\mathrm{M}$, et al. Germinated Thai black rice extract protects experimental diabetic rats from oxidative stress and other diabetesrelated consequences. Pharmaceuticals 2017;10:3.

12. Chaiyasut C, Sivamaruthi BS, Pengkumsri N, Saelee M, Kesika P, Sirilun S, et al. Optimization of conditions to achieve high content of gamma amino butyric acid in germinated black rice, and changes in bioactivities. Food Sci Technol Campinas 2017;37 Suppl 1:83-93.

13. Chaiyasut C, Sivamaruthi BS, Pengkumsri N, Sirilun S, Peerajan S, Chaiyasut $\mathrm{K}$, et al. Anthocyanin profile and its antioxidant activity of widely used fruits, vegetables, and flowers in Thailand. Asian J Pharm Clin Res 2016;9:218-24.

14. Pengkumsri N, Chaiyasut C, Sivamaruthi BS, Saenjum C, Sirilun S, Peerajan $\mathrm{S}$, et al. The influence of extraction methods on composition and antioxidant properties of rice bran oil. Food Sci Technol Campinas 2015:35:493-501.

15. Sivamaruthi BS, Pengkumsri N, Saelee M, Kesika P, Sirilun S, Peerajan S, et al. Impact of physical treatments on stability and radical scavenging capacity of anthocyanidins. Int J Pharm Pharm Sci 2016;8:162-7.

16. Kubola J, Siriamornpun S, Meeso N. Phytochemicals, vitamin C and sugar content of Thai wild fruits. Food Chem 2011;126:972-81.

17. Chaudhary B, Mukhopadhyay K. Syzygium cumini (L.) Skeels: A potential source of nutraceuticals. Int J Pharm Biol Sci 2012;2:46-53.

18. Swami SB, Thakor NS, Patil MM, Haldankar PM. Jamun (Syzygium cumini (L.)): A review of its food and medicinal uses. Food Nutr Sci 2012;3:1100-17.

19. Yadav AK, Saraswat S, Sirohi P, Rani M, Srivastava S, Singh MP, et al. Antimicrobial action of methanolic seed extracts of Syzygium cumini Linn. on Bacillus subtilis. AMB Exp 2017;7:196. 
20. Shinde J, Taldone T, Barletta M, Kunaparaju N, Hu B, Kumar S, et al. $\alpha$-Glucosidase inhibitory activity of Syzygium cumini (Linn.) Skeels seed kernel in vitro and in Goto-Kakizaki (GK) rats. Carbohydr Res 2008;343:1278-81

21. Brandao TS, Pinho LS, da Silva-Hughes AF, Souza JL, Rosa CA, Teshima E, et al. Characterization of the jambolan (Syzygium cumini L.) fruit wine processing. Bioresources 2017;12:7069-83.

22. Bona KS, Belle LP, Bittencourt PE, Bonfanti G, Cargnelluti LO, Pimente VC, et al. Erythrocytic enzymes and antioxidant status in people with Type 2 diabetes: Beneficial effect of Syzygium cumini leaf extract in vitro. Diabetes Res Clin Pract 2011;94:84-90.

23. Nishandhini S, Sudha V, Mallavarapu GR, Murugan R. Chemical compositions, $\alpha$-amylase inhibitory and antioxidant activities of the essential oils from unripe fruit pulp and leaves of Syzygium cumini. Int J Pharm Pharm Sci 2015;7:511-4.

24. Prasad M, Venugopal SP, Alagarsamy V, Sridevi C. The preliminary phytochemical analysis and oral acute toxicity study of stem bark of Syzygium cumini. Int J Pharm Pharm Sci 2016;8:209-13. 